\title{
COST-EFFECTIVE FABRICATION OF WETTABILITY GRADIENT COPPER SURFACE BY SCREEN PRINTING AND ITS APPLICATION TO CONDENSATION HEAT TRANSFER
}

\author{
TZONG-SHYNG LEU* and HUNG-MING HUANG \\ Department of Aeronautics and Astronautics, National Cheng Kung University \\ No. 1 University Road, Tainan 701, Taiwan \\ *tsleu@mail.ncku.edu.tw \\ DING-JUN HUANG \\ Department of Materials Science \& Engineering, National Cheng Kung University \\ No. 1 University Road, Tainan 701, Taiwan \\ q28991059@mail.ncku.edu.tw \\ Published 22 June 2016
}

\begin{abstract}
In this paper, wettability gradient pattern is applied to condensation heat transfer on a copper tube surface. For this application, the vital issue is how to fabricate gradient patterns on a curve tube surface to accelerate the droplet collection efficiently. For this purpose, novel fabrication processes are developed to form wettability gradient patterns on a curve copper tube surface by using roller screen printing surface modification techniques. The roller screen printing surface modification techniques can easily realize wettability gradient surfaces with superhydrophobicity and superhydrophilicity on a copper tube surface. Experimental results show the droplet nucleation sites, movement and coalescence toward the collection areas can be effectively controlled which can assist in removing the condensation water from the surface. The effectiveness of droplet collection is appropriate for being applied to condensation heat transfer in the foreseeable future.
\end{abstract}

Keywords: Surface modification; wettability gradient; screen printing.

\section{Introduction}

In recent years, global warming awareness due to industrial development gets major attention. How to efficiently use resources and reduce energy waste has become the important subject of public concerns. In the energy industry, condensers are used for waste heat and waste water recovery in steam generator power plants. How to enhance efficiency of condensers has been regarded as the focus of improvement.

Recent research efforts on surface modification have successfully proved to improve the condensation heat transfer effect ${ }^{1-6}$. Chatterjee ${ }^{4}$ investigated the CHT enhancement of

This is an Open Access article published by World Scientific Publishing Company. It is distributed under the terms of the Creative Commons Attribution 3.0 (CC-BY) License. Further distribution of this work is permitted, provided the original work is properly cited. 
island-patterned surface and tree-patterned hybrid surfaces. They adjusted the hydrophilic island diameters and the highest heat transfer was larger than that of complete hydrophobic surface. Their study expressed that the condensate water droplets mainly nucleated and grew on the hydrophilic island patterns, and the smaller island ensured the smaller droplet departure size, easier coalescence and higher departure frequency. When droplets are sitting on wettability gradient surfaces, spontaneously driving force will cause movement of the droplets. Recent research efforts on wettability gradient surface have also successfully applied to enhance the condensation heat transfer efficiency. Daniel ${ }^{5}$ utilized silane-modified Si surfaces which possessed a radial wettability gradient to study the heat transfer enhancement compared with that of a pure Si surface. In their study, the condensate droplets nucleated, and then were horizontally driven by the wettability gradient, or by the coalescence with other droplets. The superior heat transfer was attributed to the fast droplet driving effect, directly minimizing the overall condensation cycle time and enhancing more heat transfer flux per unit time. Their study is the pioneer study that a wettability gradient surface was applied to enhance CHT; Later, $\mathrm{Leu}^{6}$ proposed a composite wettability gradient silicon surface in order to apply to CHT enhancement. Compared with pure silicon, the heat flux of the modified wettability gradient silicon surface was increased by $10 \%$ because of the fast condensation and droplet falling cycle resulted by the wettability gradient. In this study, patterns with distinct wettability gradient patterns are carefully designed with due importance to the shape and size of the pattern features, as well as condensation heat transfer on the distinct wettability gradient patterns on the copper tube with will be studied.

\section{Fabrication Processes of wettability gradient surface on copper tube}

The fabrication process of a wettability gradient copper tube surface is shown in Fig. 1 and detailed fabrication processes are described in the following steps.

\subsection{Copper surface clean (Step 1 2 in Fig. 1)}

First, copper tube surface with outer diameter $15.875 \mathrm{~mm}$ and length $384 \mathrm{~mm}$ were immersed in $15 \mathrm{wt} \%$ nitric acid $\left(\mathrm{HNO}_{3}\right)$ solution with appropriate stirring for $15 \mathrm{~min}$ to remove the native oxide on copper tube surface. Next, the cleaned copper tube surface were immersed in a $30 \mathrm{wt} \%$ hydrogen peroxide $\left(\mathrm{H}_{2} \mathrm{O}_{2}\right.$, J. T. Baker, U.S.A.) solution for at least $30 \mathrm{~min}$, and the copper tube surface was modified as a roughened surface that composed of $\mathrm{CuO}$ nanowire structures. After immersion, the roughened copper tube surface was rinsed by deionized water and dry by air. The pretreatment of a copper tube surface was finished by heating copper surface at $60{ }^{\circ} \mathrm{C}$ about $5 \mathrm{~min}$. 
1.Cu cleaned with $\mathrm{HNO}_{3}$

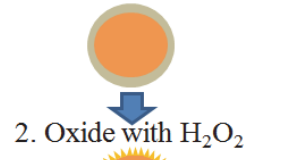

3.Screen Printing

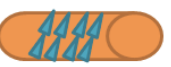

4.EGC coating on $\mathrm{Cu}$
5.Telfon coating on $\mathrm{Cu}$
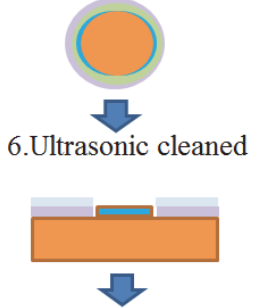

7. Oxide with $\mathrm{H}_{2} \mathrm{O}_{2}$

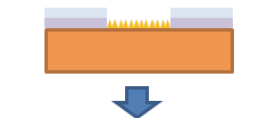

8.Measure contact angle

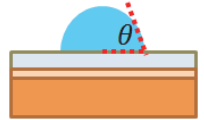

Fig. 1. Fabrication process of a wettability gradient copper tube surface by using a roller screen printing technique.

\subsection{Screen printing (step 3)}

Screen printing was used to define patterns on the copper tube surface. Before the screen printing process, wettability gradient patterns and stenciled mesh screen are designed and fabricated, as plotted in Fig. 2. Fig. 2a shows the triangular wettability gradient pattern design with the apex angle $8^{\circ}$. There are two rows of wettability gradient pattern array on each side of copper tube. Wettability gradient pattern array will cover $3.5^{\circ}$ to $116.5^{\circ}$ on each side of copper tube. Next, a stenciled mesh screen was fabricated and shown in Fig. 2b. For the stenciled mesh screen, the mesh web is made of nylon with a rectangular aluminum frame. The roller screen printing platform with stenciled mesh screen is shown in Fig. $2 b$.

The roller screen printing platform with a special type of blue ink during printing is shown in Fig. 3a. The special anti-acid blue screen printing ink (Item No. NS-150, Photo Cure Co., Ltd.) is mainly composed of synthetic resins and auxiliary chemicals. At beginning, the copper tube was placed on the platform, and a stenciled mesh screen was installed and locked above the copper tube surface. At this step, appropriate height between the stenciled mesh screen and the copper tube surface can be adjusted. Next, appropriate amount of ink is pouring onto the stenciled mesh screen. The squeegee was squeezed on the top of screen when stenciled mesh screen frame rolls over the copper tube back and forth with a squeezer on the top and ink was pressed and printed on the copper tube surface through the opened mesh areas. Afterward, the ink-printed copper substrates were heated at temperature $100{ }^{\circ} \mathrm{C}$ for $10 \mathrm{~min}$ to consolidate the printing ink 
layer on substrates. Fig. $3 \mathrm{~b}$ shows the photo of the blue ink-printed triangular patterns on the copper tube surface.

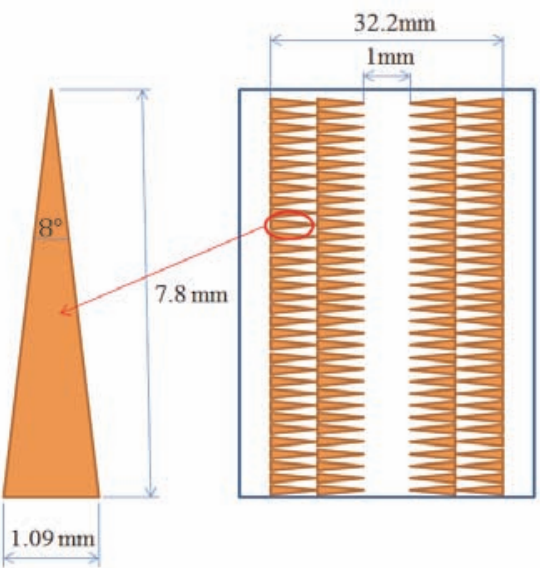

(a)

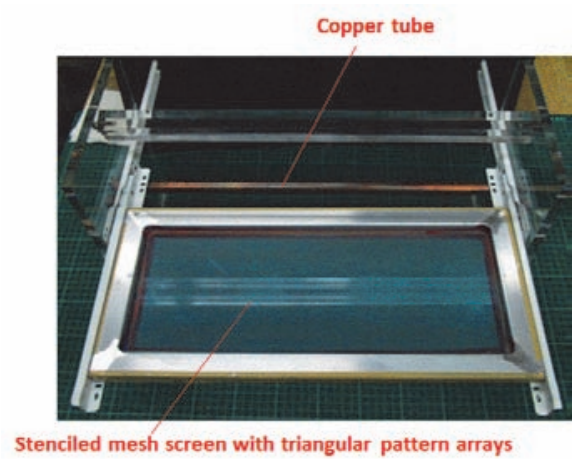

(b)

Fig. 2. (a) Triangular wettability gradient patterns design, (b) Photo of the roller screen printing platform and stenciled mesh screen with triangular pattern arrays.

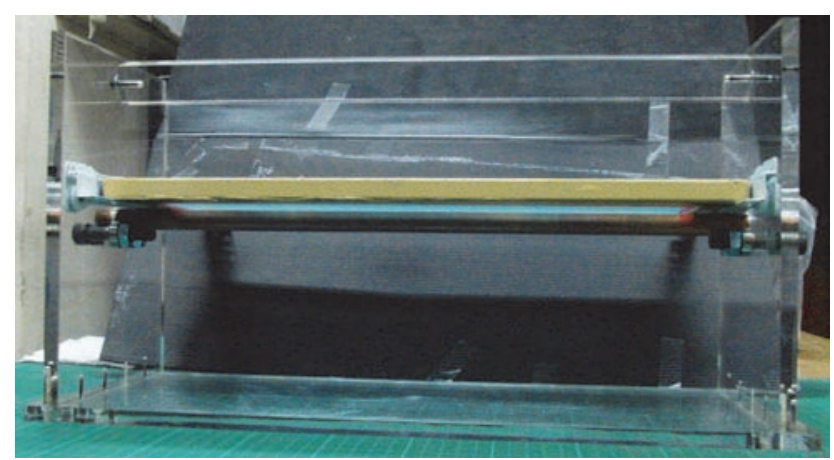

(a)

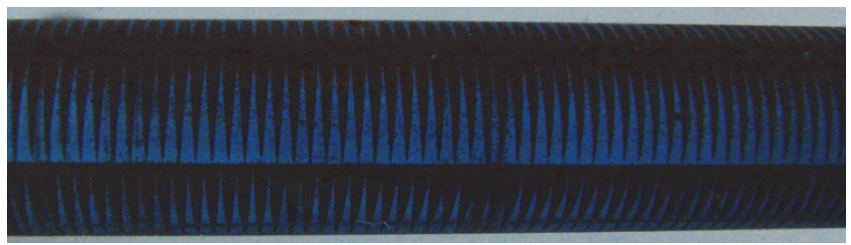

(b)

Fig. 3. (a) Roller screen printing platform during stenciled mesh screen frame rolling over the copper tube, the copper tube were placed underneath the stenciled mesh screen. (b) Photo of the screen printed triangular blue ink patterns on the copper tube surface. 


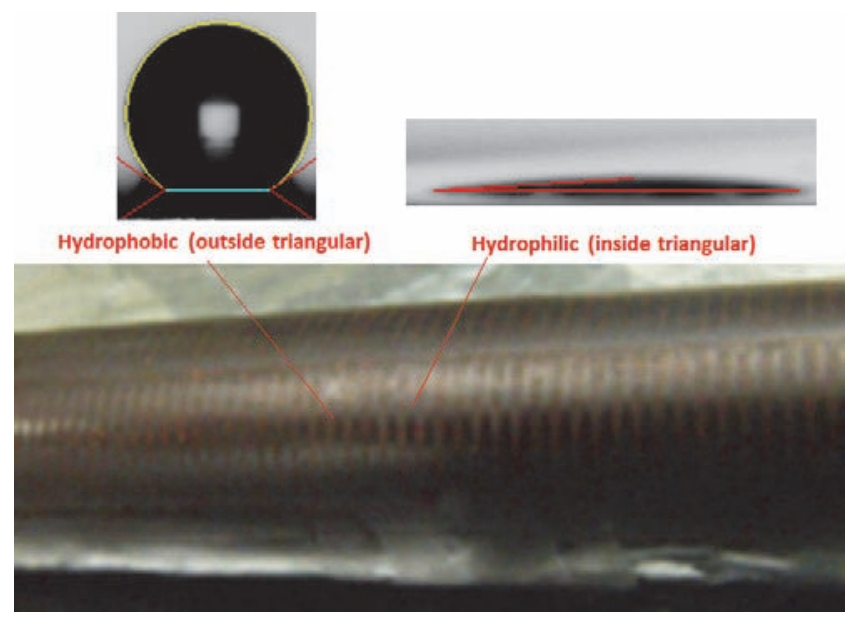

Fig. 4. Photo of fabricated gradient wettability patterns on the copper tube surface.

\subsection{Surface modification process (step 4 7)}

The ink-printed copper surface was dip-coated with EGC-1720 solution for $3 \mathrm{sec}$. After the EGC-1720 dip coating, the copper surface was heated at temperature $110^{\circ} \mathrm{C}$ for 30 min to evaporate the solvent. $5 \mathrm{wt} \%$ Teflon solution was prepared by mixing Teflon (1601S-100-6, Dupont Inc., U.S.A.) with FC-770 fluorinert liquid (3M Inc., U.S.A.). When EGC-1720 coated copper substrates were immersed in the prepared Teflon solution for $3 \mathrm{sec}$, EGC-1720 fluorosilane coating on the copper surface serves as the adhesive between Teflon and the copper surface. Later, the Teflon-coated copper plates were immersed in an ultrasonic cleaner (Model No. 8891-DTH, Cole-Parmer Inc., U.S.A.) to strip off the ink layers by using butanone (Methyl ethyl ketone, J.T. Baker, U.S.A.). After stripping, the Teflon-coated copper substrates were rinsed by water, dried by air, and heated at $110^{\circ} \mathrm{C}$. To enforce the Teflon coating, the copper substrates were heated at $160{ }^{\circ} \mathrm{C}$ for $5 \mathrm{~min}$, and then at $330{ }^{\circ} \mathrm{C}$ for $15 \mathrm{~min}$. Finally, the copper substrates were immersed in $30 \mathrm{wt} \%$ hydrogen peroxide $\left(\mathrm{H}_{2} \mathrm{O}_{2}\right)$ solution for $15 \mathrm{~min}$ to restore the hydrophilicity inside the triangular pattern of the copper tube surface. Fig. 4 shows the photo of fabricated gradient wettability patterns on the copper tube surface. The final gradient wettability copper tube surface shows well defined hydrophilic patterns on copper substrate is shown in Fig. 4. The contact angle on hydrophilic areas is $7.47^{\circ} \pm$ $3.32^{\circ}$ which can be seen in the upper-right inset of Figure 4. Areas outside triangular pattern are Teflon-coated areas that remain superhydrophobicity on the copper tube surface. From the upper-right inset in Fig. 4, the contact angle on the superhydrophobic surface is $146.01^{\circ} \pm 8.45^{\circ}$. 


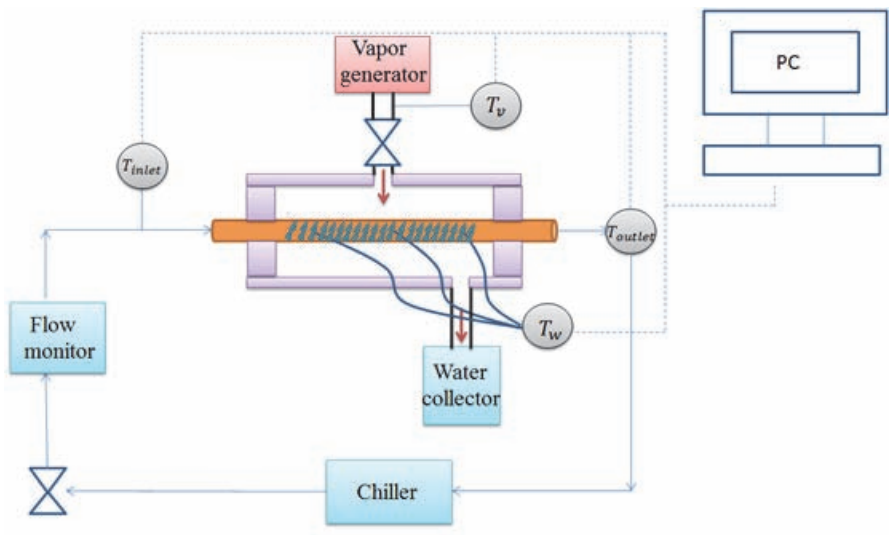

(a)

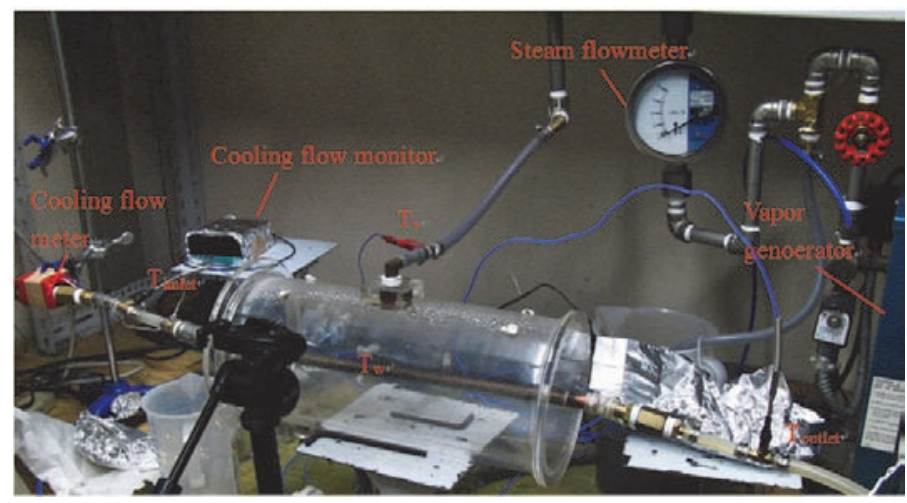

(b)

Fig. 5. Photo of fabricated gradient wettability patterns on the copper tube surface.

\section{Experimental Setup}

The experimental setup is composed of one condensation tube in condensation chamber, and both of them are as shown in Fig. 5a. The condensation tube is used to condense vapor on the condensation surface, which is namely the fabricated wettability gradient array surface mentioned before. The effective area of the condensation surface was approximately $19140 \mathrm{~mm}^{2}$ (as shown in Fig. 5b). Technically, the chamber material used was acrylic in order to minimize the heat transfer to the chamber in experiment. After the fabricated copper tube was installed in the chamber, all required facilities were connected (like that shown in Fig. 5a). The tube allowed cooling water to be transported by a pump. Rotameter flow meters were employed to control the flow rate of cooling water. The measured range was from $4,000 \mathrm{cc} / \mathrm{min}$ to $8,000 \mathrm{cc} / \mathrm{min}$. K-type thermocouples (NI USBTC01, National Instruments, U.S.A.), were used to measure the temperatures of cooling water inlet $\left(\mathrm{T}_{\text {inlet }}\right)$, outlet $\left(\mathrm{T}_{\text {outlet }}\right)$, vapor temperature $\left(\mathrm{T}_{\mathrm{v}}\right)$ and condensation surface temperature $\left(\mathrm{T}_{\mathrm{w}}\right)$ respectively. Vapor was provided by an electric steam generator. The 
vapor flowing into the condensation chamber condenses causes water droplets nucleation and growth on the condensation surface. CCD camera (Casio EXILIM Pro EX-F1) was used to capture real time videos and photos of the surface condensation features (300 frames per second). Fig. $5 \mathrm{~b}$ shows the photo of the experimental setup.

\section{Results and discussion}

The captured photos of droplet behaviors on hydrophilic, hydrophobic and wettability gradient array surfaces are shown in Fig. 6. In Fig. 6a, the droplet condenses on hydrophilic copper tube surface was demonstrated. Fig. 6a shows nucleation droplets form a liquid film on the copper tube surface. Filmwise condensation behaviors are found in this case. Fig. 6b shows dropwise condensation behaviors on the hydrophobic copper surface. Droplets with diameter greater than $2.5 \mathrm{~mm}$ are still sit on the copper tube surface. The droplet condensation on wettability gradient patterns with $\psi=8^{\circ}$ on copper tube surface was demonstrated in image sequence of Fig. 7. Fig. 7 shows condensation droplets with diameter smaller than $2.5 \mathrm{~mm}$ (circle in Figs. $7 \mathrm{a} \& 7 \mathrm{~b}$ ) are able to slide downward along the wettability gradient regions. Moreover, the condensate droplets from the same row of gradient arrays directly collect near the triangular base of the wettability gradient patterns, as shown in Fig. 8.

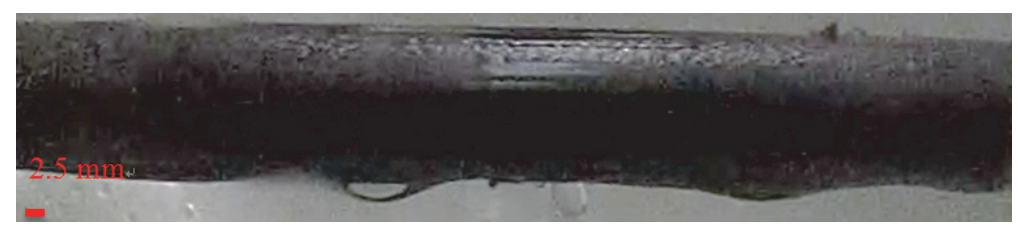

(a)

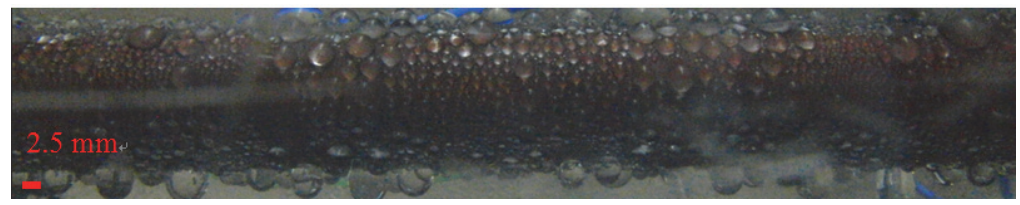

(b)

Fig. 6. Photo of droplet behaviors on the (a) hydrophilic and (b) hydrophobic copper tube surface.

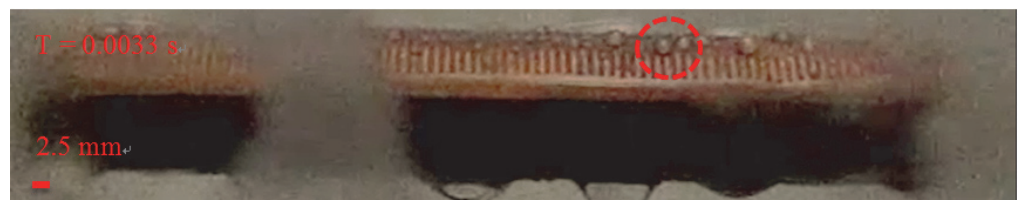

(a) 


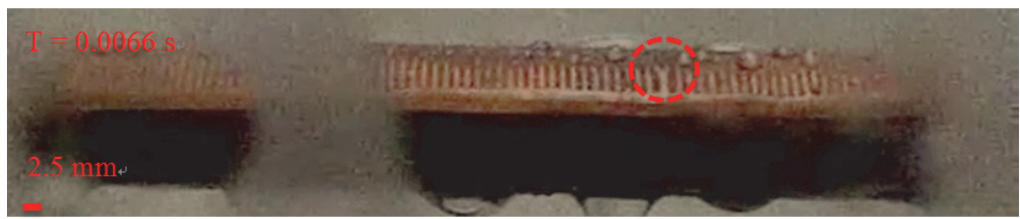

(b)

Fig. 7.Image sequence of droplet behaviors on the wettability gradient copper tube surface at time (a) $\mathrm{T}=0.0033 \mathrm{sec}$ and $(\mathrm{b}) \mathrm{T}=0.0066 \mathrm{sec}$.

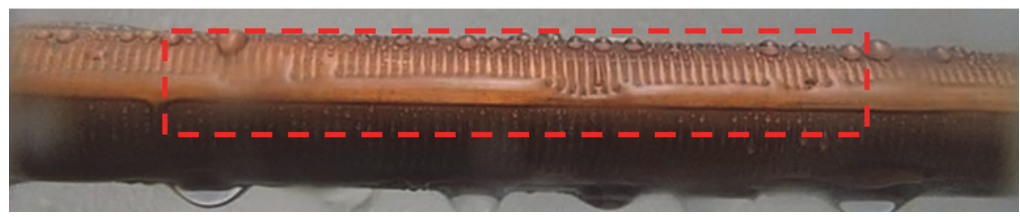

Fig. 8. Photo of droplet collection near the triangular bases of the wettability gradient patterns on copper tube surface before falling down.

\section{Conclusions}

Triangular wettability patterns are applied in the condensation heat transfer experiments of this study. The triangle pattern arrays form wettability gradient surface on the copper tube surface. Compared with the condensation droplet behaviors on the hydrophilic, hydrophobic and wettability gradient surface on a copper tube, droplets on wettability gradient surfaces show the movement with smaller droplet size and better condensation droplets collection. Experimental results also show copper tube with wettability gradient surfaces can move the nucleation droplets with smaller diameter and effectively collect and remove the condensation liquid from the surface.

\section{Acknowledgements}

Funding for this research project is supported by Ministry of Science and Technology under the contract of NSC 102-2221-E-006-091-MY3.

\section{References}

1. B. Peng, X. Ma, Z. Lan, W. Xu and R. Wen, Int. J. Heat Mass Transfer, 83:27-38, (2015).

2. D.J. Huang and T.S. Leu, Appl. Therm. Eng., 75:908-917, (2015).

3. N. Miljkovic, R. Enright, Y. Nam, K. Lopez, N. Dou, J. Sack and E.N. Wang, Nano Lett., 13:179-187, (2012).

4. A. Chatterjee, M.M. Derby, Y. Peles and M.K. Jensen, Int. J. Heat Mass Transfer, 71:675-681, (2014).

5. S. Daniel, M.K. Chaudhury and J.C. Chen, Science, 291:633-636, (2001)

6. T.S. Leu, H.W. Lin and T.H. Wu, Mod. Phys. Lett. B, 24:1381-1384, (2010) 